ASLI QoL 2017

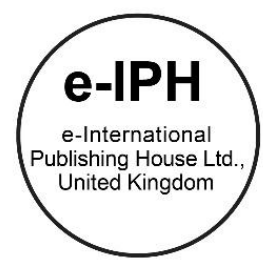

\title{
Promoting Ageing-in-Place: Design of residential buildings for older people in China
}

\author{
Tulika Gadakari ${ }^{1}$, Jingjing Wang ${ }^{2}$, Karim Hadjii ${ }^{2}$, Junjie Huang ${ }^{2}$ \\ ${ }^{1}$ School of Art and Design, Coventry University, Priory Street, Coventry CV1 5FB, UK \\ ${ }^{2}$ School of Architecture, The University of Sheffield, Western Bank, Sheffield S10 2TN, UK \\ tulika.gadakari@coventry.ac.uk \\ Tel: +44 (0) 2477658374
}

\begin{abstract}
Ageing-in-place is the most common ageing model in China. Therefore, design of age-friendly residential buildings and neighbourhoods becomes an important factor leading to improvement in older people's health and quality of life. This paper presents the current situation of the ageing population in Chinese cities by qualitatively analysing existing literature, design standards and conducting stakeholder interviews to understand older people's housing choices as well as establish physical design factors, challenges and potentials of residential design for older people. The findings will fill the knowledge gap of age-friendly residential models in China and guide better design to meet older people's needs.
\end{abstract}

Keywords: ageing; age-friendly design; residential building; spatial design

eISSN: 2398-4287@ 2017. The Authors. Published for AMER ABRA by e-International Publishing House, Ltd., UK. This is an open access article under the CC BYNCND license (http://creativecommons.org/licenses/by-nc-nd/4.0). Peer-review under responsibility of AMER (Association of Malaysian Environment-Behaviour Researchers), ABRA (Association of Behavioural Researchers on Asians) and cE-Bs (Centre for Environment-Behaviour Studies), Faculty of Architecture, Planning \& Surveying, Universiti Teknologi MARA, Malaysia.

https://doi.org/10.21834/e-bpj.v2i6.965

\subsection{Introduction}

The global population is undergoing a marked demographic shift, where older people will soon outnumber youth populations owing to increase in life expectancy, falling fertility rates, and lifestyle changes. The number of people aged 65 or older is projected to grow from an estimated 524 million in 2010 to nearly 1.5 billion in 2050, with most of the increase in developing countries. (World Health Organisation, 2011) In China, people aged 60 and over are defined as 'older people' and this population is rising rapidly due to an overall increase of life expectancy of 29.8 years since the 1960s to 2010 (OECD, 2014). The number of Chinese people over the age of 65 are likely to grow from 123 million in 2011, 200 million in 2026, 300 million in 2038, to 330 million by 2050, with around 100 million over the age of 80 (World Health Organisation, 2011; United Nations, 2013; OECD, 2014). According to China's Ministry of Civil Affairs, the number of people aged 60 and over is currently 222 million, which comprises of $16.1 \%$ of the total population and has already surpassed the above prediction (CIIC China, 2016).

In tandem with demographic change, China is also undergoing massive social and economic transitions. The country is witnessing key changes in family structures, urbanisation, educational advancement, technological development and increasing participation of women in the labour market. These shifts are challenging the traditional family-based care arrangement for older people. In the future, for every younger couple there will be four or more older family members who require daily care and assistance. (Feng, 2014) This will have direct consequences in terms of access to social care and financial security, and may even influence the quality of life.

\subsection{Ageing-in-Place}

According to Davey, de Joux, Nana, \& Arcus (2004), ageing-in-place is defined as "remaining living in the community, with some level of independence, rather than in residential care". It is a way in which older people can manage their homes and live with greater

eISSN: 2398-4287@ 2017. The Authors. Published for AMER ABRA by e-International Publishing House, Ltd., UK. This is an open access article under the CC BYNCND license (http://creativecommons.org/licenses/by-nc-nd/4.0/). Peer-review under responsibility of AMER (Association of Malaysian Environment-Behaviour Researchers), ABRA (Association of Behavioural Researchers on Asians) and cE-Bs (Centre for Environment-Behaviour Studies), Faculty of Architecture, Planning \& Surveying, Universiti Teknologi MARA, Malaysia.

https://doi.org/10.21834/e-bpj.v2i6.965 
autonomy, choice and control while maintaining their emotional attachments to family and community, without the cost and hassle of moving (Best \& Porteus, 2016).

According to the National Bureau of Statistics of the People's Republic of China (2016), home-based ageing model is the most common in China. China has a long familistic history and people are keen to uphold the traditional practice of family-based care rooted in the ideological foundation of filial piety and mutual support, thus preferring to age-in-place (Zhou \& Walker, 2016). Although family support systems are weakening due to the growth of individualism, urbanisation and mass migration, the family and home -based care models still occupy a large proportion of care models for the older population in China (Zhang \& Goza, 2006; Li, 2010). The results from the National Bureau of Statistics of the People's Republic of China (2016) reiterates the same by listing the reasons as to why older people chose a home-based care model in the Zhejiang province:

a) $84.2 \%$ convenient, free life

b) $51.3 \%$ the company of family

c) $35.8 \%$ familiar living environment

d) $34.9 \%$ saving money

e) $5.1 \%$ difficult to find suitable care home

f) $2.1 \%$ feel shame to go to care home

In the Chinese context, one must acknowledge that community care is often perceived as an alternative to institutional care and there is no clear boundary between 'home care' and 'community care' (Tian, 2010). Home care service is defined as, a government and social force that is based in the community, which provides a wide range of health and social services such as day care, housekeeping service, rehabilitation care, canteens, centralised meal delivery and spiritual comfort for older people to age-in-place (Tian, 2010; Zhou \& Walker, 2016).

Pannell \& Blood (2012) and Torrington (2014) identify, mobility support, sensory support, support for cognitive failings and health and safety, as key while adapting homes or local neighbourhoods for older people to age-in-place. There is significant evidence that making homes more accessible, with better spatial configuration, can reduce the need for care, reduce falls, increase independence and improve quality of life (Iwarsson \& Ståhl, 2003; Burmeister, 2010; Best \& Porteus, 2016). Additionally optimising lighting, maintaining comfortable temperature, providing good outdoor spaces, views and tonal contrasts makes it comfortable, healthier and safer for older people (Roelofsen, 2014; Hussein, Omar, \& Ishak, 2016; Gupta, Barnfield, \& Gregg, 2017). Personalisation of space, use of design prompts, colours to 'theme' areas, meaningful artwork, pictorial signage and pictures can help orientate older people with dementia and other cognitive impairments. An environment that is designed to be intuitive and easy to use can enable older people to experience a sense of competence, choice and control, thus making a positive difference to a person's self-esteem (Faith, Hadjri, Rooney, Craig, \& McAllister, 2015; Twyford, 2016; Walker, 2017).

Ageing in familiar surroundings has shown to have a positive correlation with health and well-being and sense of satisfaction and contentedness (Renaut, Ogg, Petite, \& Chamahian, 2015; Hussein, Abidin, \& Omar, 2016; Stones \& Gullifer, 2016; Dahlan \& Sultanlbrahim, 2017; Yousefi, Hosseini, Yazdanfar, \& Norouzian-Maleki, 2017). Older people wanting to remain in their homes and communities for as long as possible helps in the maintenance of social connection and support from family and friends (Lawler, 2001; Muhammad, 2016; Zakariya, Harun, \& Mansor, 2016). Additionally, ageing-in-place is also an option to avoid the expensive choice of institutional care and is therefore favoured by policy makers, health providers, and by many older people themselves (World Health Organization, 2007). However, ageing-in-place may not be a perfect option for older people who face various challenges, such as dementia, visual impairment, acute mental illness or financial issues (Kang, Lyon, \& Kramp, 2012).

The use of technology is actively enabling aspects of ageing-in-place by transforming the way health, social care and other assistive services are designed and delivered (HACT, 2016; Local Government Association \& Institute of Public Care, 2016; Agile Ageing Alliance, 2017). Systematic mapping of current advances in assistive technology revealed that health is the main purpose for people to use assistive technologies (Labonnote \& Høyland, 2015) and the most equipped room in the house is the kitchen (Gibson, Dickinson, Brittain, \& Robinson, 2015). By interviewing older people that currently use assistive technology, Jennings, Hadjri, \& Abdelmonem (2012) discovered that security was a main factor that motivated the use of technology.

\subsection{Residential Design: current situation in China}

The home environment is a vital consideration and determinant for daily activities and participation for the older generation. Specifically, the physical settings of housing help support independent living, and is a critical indicator for older people who wish to continue to live a normal life at home for as long as possible. (Iwarsson \& Wilson, 2006) The home environment plays an important role in later life as it becomes increasingly relevant to older people's health who spend most of their time at home, far more than any other setting (Danziger \& Chaudhury, 2009). Danziger \& Chaudhury (2009) propose that if environmental factors were to match the individual's capabilities, frailty can be delayed, more independence can be achieved, and vulnerability and risk of injuries can be reduced. Zhang, Liu, \& Qi (2015) establish, living arrangement (live with children or not); social connection between neighbours; shopping facilities; health facilities; recreation centre and fitness facilities; sense of community; community activities; level of property management, as factors that impact the life satisfaction of older people in China.

According to Shu (2006), the homeownership rate of Chinese older people in urban areas is $82.1 \%$, which is the highest rate in the world. There are a number of housing types currently available in urban China such as, the traditional si he yuan courtyard, new build commercial housing, unit compound (staff accommodation), affordable housing community, low price housing community and combination housing community $(\mathrm{GaO}, 2013)$. Li (2010) reports, the source of older people's housing is varied:

a) $40.9 \%$ of houses are ancestral (mostly owned by farmers) 
b) $18.8 \%$ of houses for older people are allocated by the employer (or previous employer)

c) $14.1 \%$ are second-hand buys

d) $11 \%$ of older people buy affordable housing

e) $8.2 \%$ have commercial housing

According to the China Health and Retirement Longitudinal Study (2013), which is a nationally representative sample of Chinese residents, ages 45 and older, $45.7 \%$ of older people live in multi-storey buildings, while only $22 \%$ of buildings have handicapped facilities such as ramps and $12.9 \%$ of buildings have more than 25 steps to access the main entrance.

Family structures and living arrangements greatly influence the area of homes in China. From a sample size of 420 respondents (Zhang, Liu, \& Qi, 2015) a family of two (43.3\%) is the most common type for older people, closely followed by the family of five (21\%) and four (18.1\%). $49.4 \%$ of $60-70$ year olds co-reside with their children and the percentage rises to $58 \%$ as people age over 80 years. $85.9 \%$ of $60-70$ year olds live with their partner, while only $38.2 \%$ of people over the age of 80 years live with their partner. (China Health and Retirement Longitudinal Study, 2013) The housing area of older people in Beijing is about $50-100 \mathrm{~m}^{2}$, and is proportional to the number of family members. Older people living alone mainly occupy $50 \mathrm{~m}^{2}$ or less; a family of two usually occupies $50-100 \mathrm{~m}^{2}$; and a family of five usually occupies $100-150 \mathrm{~m}^{2}$. (Zhang, Liu, \& Qi, 2015) $5.2 \%$ of older people or couples occupy less than one room; $25.5 \%$ have one room; $24.5 \%$ have two rooms; $20.6 \%$ have three rooms; $14.3 \%$ have four rooms and $9.8 \%$ have five rooms. Based on this data (Li, 2010), $24.3 \%$ of respondents' living space is spacious, while $30.8 \%$ respondents do not have enough living space.

\subsection{Current building design standards for ageing populations}

Currently there are a number of building standards for inclusive design all over the world, which align with inclusion requirements and disability acts. For example, the UK Part M building standards and the UK Lifetime Homes Standards aim to make the home more accessible and inclusive of disabled and older people. The US ADA Standards for Accessible Design are enforceable accessibility standards. Some of the other building design standards for older people include, Accessible Design for the Built Environment, Canada; Recomendaciones de Accesibilidad, Mexico; Design for access and mobility, Australia; Malaysian Code of Practice on the Accessibility and Mobility of Persons with Disabilities, Malaysia; and Guidelines and Space Standards for Barrier Free Built

Environment for Disabled and Elderly Persons, India. (Hadjii, Afacan, \& Gadakari, 2016)

The latest design standard for older people in China titled 'Code for design of residential building for the aged' is suitable for newbuilds, extensions and reconstruction of residential buildings. This standard aims to meet older people's need for safety, accessibility, health, cost-effectiveness and environmental sustainability by employing 30 criteria under 5 categories (MOHURD \& AQSIQ, 2017):

1) Site and planning- considers elements such as adequate sunlight, ventilation, access to public transport, barrier-free walking paths, wheelchair pathways, handrails, recreational facilities, accessible toilets, wayfinding systems, green coverage, stairs, etc.

2) Public space- considers elements under sub-sections of entrance; public walkway; stairs and lifts; and emergency evacuations.

3) Space within the dwelling unit- introduces adequate dimensions for each living area; minimum living space per person; minimum wheelchair turning area; window heights for wheelchair eye level; space to meet future needs for adaptations; etc.

4) Physical environment- considers indoor environment under the categories of acoustics; lighting; heating/cooling; and ventilation

5) Building equipment- includes standards for equipment needed for water supply and sewerage system, fire protection and smoke management, heating and ventilation, alarms and emergency call systems, motion sensors, etc.

\subsection{Aims and Objectives}

This paper aims to understand older people's housing choices as well as establish physical design factors, challenges and potentials of residential design for older people in China. In order to achieve this, the following objectives have been set out:

1) To analyse existing literature and design standards for older people's environments in China;

2) To conduct stakeholder interviews with Chinese experts in the field of ageing and the built environment; and

3) To develop a set of recommendations, which will fill the knowledge gap of age-friendly residential models in China and guide better design to meet older people's needs.

\subsection{Methodology}

A list of academic researchers and practitioners who are experts in the field of ageing and have been involved in projects for older people in China was compiled. These experts were contacted by phone and email to gauge their interest in the study and asked whether they would be willing to be interviewed. Nine experts agreed to be interviewed via telephone, which included: Professor (Social Science) and Associate Professor (Architecture), Tsinghua University, Beijing; Professor (Social Science), Chinese Academy of Sciences, Beijing; Professor (Interior Design) and Associate Professor (Environmental design), Beijing Union University, Beijing; Chief Designer (Interior and Product Design), Beijing; Design Director (Architect), China Construction Design International (CCDI), Shanghai; Chief Architect, Shanghai; and Architect, Hunan Province.

The interview questions were developed based on findings from the literature review and previous research by the authors and were concerned with housing choices, physical design factors, challenges and potentials of residential building design for older people. The interview schedule contained fourteen questions as follows:

Q1) From your experience of designing for older people, what would be the major design factors to consider that can support their ageing-in-place needs? Can you prioritise these factors according to your opinion? 
Q2) Are you aware of any specific standards, or design guidelines for older people's living environment? During your design process, do you refer to them? How important do you think these standards or design guidelines are?

Q3) Are you aware of government policies regarding the ageing industry in China? Do these policies influence or guide your design project in any way?

Q4) According to research data, many older people are currently living in overcrowded conditions in China. In your opinion, is it possible to change this situation by designing in a more efficient way (architectural/interior design)? Can you provide any examples?

Q5) In China, some older people are currently living with their children or even grandchildren. From your point of view, is it possible to better support multi-generational living by means of architectural design? Can you provide any examples?

Q6) Meanwhile, there are also some older people who choose to live alone or with their partners in order to not put much pressure on their children. How do you think we can support these older people through design?

Q7) While conducting refurbishment or reconstruction, which elements or conditions of the existing environment could potentially become design barriers?

Q8) In the housing projects, how could the design better adapt to current residents' future needs as they get older?

Q9) How do you think financial affordability affects older people's decision to refurbish, reconstruct and adapt their homes?

Q10) In your opinion, how to reflect human-centred care through housing design? How do you maintain the balance between humancentred care and the value of design? Can you provide any examples?

Q11) How to maximise the feeling of home through the use of architecture/interior design in care home settings? Can you provide any examples?

Q12) Are you aware of any assistive technology which can provide or is providing support to older people so as to create a more independent, healthy, and safe living environment?

Q13) Do you think community care is important for ageing? In what way can the design of community affect older people's everyday lives?

Q14) What is your understanding of ageing-in-place? In your opinion, why do you think older people in China prefer to age-in-place?

The purpose and duration of the interviews were explained to the experts at the start of the interviews. The interviews were designed to be semi-structured and hence the researchers remained as neutral as possible, encouraged responses, did not interrupt and allowed silences to give participants time to think. The interviews were audio recorded, then transcribed verbatim, translated from Chinese to English and thematically analysed. The researchers familiarised themselves with the data, which involved reading and rereading the text to spot similarities, differences, and contrasts. Themes were established, reviewed and refined collaboratively between four members of the research team at regular meetings to ensure reliability, consistency, and to minimise bias. Differences of opinions concerning the definition of themes were resolved through group discussions. Ethical approval for the interviews was obtained from the University of Sheffield's Research Ethics and Integrity Committee.

The experts were selected due to their unique knowledge and contribution to the field of ageing and the built environment in China. The research could be limiting due to the small sample size and that the experts are only from Beijing, Shanghai and the Hunan province.

\subsection{Results and Discussion}

In addressing the current situation of the existing housing choices available to older people in China and the design issues, challenges and potentials associated with these, this paper focuses on five particular, but interconnected aspects of the experts' experiences. The interviewees gathered upon their knowledge and expertise as academic researchers and design practitioners to address the themes of design, spatial requirements, emotional factors, community and technology as highly important factors to improve the future of agefriendly residential models in China to enable older people to age-in-place.

\subsection{Design}

Health and safety was unanimously prioritised as the most important factor to consider while designing for older people, followed by accessibility, sensory and then cognitive factors. Most experts added, a familiar environment that was convenient, comfortable and flexible which catered to social and psychological needs should be considered in parallel to the above factors. The common design factors highlighted by the experts, which enable ageing-in-place are thematically divided as follows:

Table 1. Design factors that enable ageing-in-place

\begin{tabular}{|c|c|c|c|c|}
\hline Accessibility & Sensory & Health \& Safety & Cognitive & Social \\
\hline Spacious rooms & Natural light & Anti-slip flooring & Familiar environment & Community centres \\
\hline Wide corridors \& doors & $\begin{array}{l}\text { Motion sensor controlled } \\
\text { lights }\end{array}$ & Design to prevent falls & $\begin{array}{l}\text { Design to create memory } \\
\text { triggers }\end{array}$ & $\begin{array}{l}\text { Activity areas for dancing, art, } \\
\text { calligraphy, music, etc. }\end{array}$ \\
\hline Wheelchair ramp & Close to floor lighting at night & Rounded furniture & Photos of children, memories & Religious buildings \\
\hline Turning area for wheelchairs & Ventilation & $\begin{array}{l}\text { Lifts to accommodate } \\
\text { stretchers \& hospital beds }\end{array}$ & $\begin{array}{l}\text { Design that encourages } \\
\text { purpose and routine }\end{array}$ & Public toilets \\
\hline $\begin{array}{l}\text { Lowered furniture height for } \\
\text { kitchen worktops, cabinets, } \\
\text { wardrobes, etc. }\end{array}$ & Thermal comfort & $\begin{array}{l}\text { Community Health Care } \\
\text { facilities (consultation, } \\
\text { rehabilitation, management) }\end{array}$ & $\begin{array}{l}\text { Senior education schemes by } \\
\text { the community }\end{array}$ & Public seating \\
\hline
\end{tabular}


Modifications in bathroom, toilet \& kitchen

Walk-in showers

Handrails and grab bars

No thresholds

Automatic \& sliding doors

Comfortable stair gradients

Structural flexibility for future

adaptation

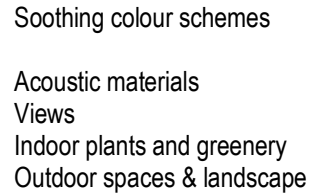

Dual opening doors to prevent locking in

Extra storage for medicines
Community library \& theatre

Public spaces that feel safe
Local amenities (shops, public transport, etc.)

Walking pathways

All the experts responded that the building design standards for older people were important and guided their design process as well as their research, though they agreed that the current design standards in China were still at an early developmental stage and need to be more detailed; focus on older people's health and ergonomics; provide more information on assistive technologies; reflect more design flexibility; be sensitive to older people's needs and issues; and cater to the significant differences in the northern and southern parts of China in terms of climate and lifestyle. Two of the experts who had experience in rural design shared that there were currently no design standards for older people in rural settings. This resulted in most practitioners relying on the ability and experience of rural builders which though gave them more freedom in terms of design but also elevated the risks.

The question regarding government policies for the ageing industry in China gathered mixed responses which ranged from very good to 'hollow promises with few practical solutions'. Some of the experts believed that the government was implementing a number of effective policies in areas of foreign investment, pension system, vouchers and gift cards, support to build community centres, encouragement of public-private partnership models, job placements and postponement of retirement age. Some of the experts added that the policies needed to be detailed, put into practice and the government needed to provide more community level care services, train care professionals and improve infrastructure.

Some of the experts noted that though some old 6-7 storey buildings in China were being refurbished by adding lifts externally there were issues with cost sharing, blockage of views and excessive noise. Limited space was also perceived as a barrier to refurbish buildings in the old parts of Beijing city especially when surrounding buildings impacted access to adequate natural light and ventilation. Most experts suggested that flexible design should be encouraged for future adaptability though in their practical experience they had struggled with the structural framework (mainly loadbearing walls) that limited their design intentions of opening up interior spaces for better mobility and natural light. Additionally, the wooden structures of rural and traditional buildings posed a limitation in this aspect. The experts noted that modifications in the bathroom which involved replacing the bathtub with a walk-in shower and adding grab bars were most needed. Some of the experts identified that traditional home design should be encouraged with the incorporation of new environmentally friendly technologies for maintaining better standards of thermal comfort, lighting, acoustics, etc. An expert noted that designers should avoid going overboard with the design features that made a person 'feel old' by blending the clinical/institutional aspects with the rest of the décor.

Several common themes emerged when financial affordability for home refurbishment was discussed and the opinions were unanimous. Most experts felt that a certain socio-economic section of Chinese older people could not afford refurbishment of their homes with their meagre pension and savings. At the same time, most experts concurred that there is a rising affluent middle class in China which can afford to spend money on home improvement but the consumer attitude of this older generation is very different and they are quite frugal. The older people belonging to this section would avoid spending their money owing to lack of time and effort, saving money for their family and lack of awareness. It was believed that this situation could be remedied by the government providing part funding or subsidiaries and raising awareness of modern design and technology.

\subsection{Spatial Requirements}

The experts were of the opinion that overcrowding was predominantly an urban issue and older people in rural parts of China had enough space as they were experiencing the 'empty nest syndrome' with most young people moving to the cities for better opportunities. Most experts agreed that better design and innovative solutions would make a huge difference to the living environment in crowded homes. Three of the experts shared their experience of refurbishing small homes for older people where multifunctional furniture (such as height adjustable kitchen worktops, cabinets, etc.), well-designed storage, clearing out cluttered paths and improved natural light, were employed to improve accessibility, safety and the 'experience of the home'.

One of these experts introduced the concept of 'time sharing' where multiple spaces in the home can be used for different functions at different times of the day, by various family members, so as to promote multigenerational living in tight spaces. Most of the experts agreed that conscious design which considered both the generations' varied lifestyle, promoted 'co-working' and communication within families were key to resolving multigenerational family conflicts. Differing sleeping patterns of the generations sharing a home were considered to be the most disruptive. Providing better acoustics so that different generations could function without disturbing each other and be mindful of privacy needs was considered key by most experts.

Some experts suggested that if the family could afford to, then they should invest in two apartments within the same community so that everyone can have their own independent space and reduce family conflicts while staying close to one another for care and emotional support. Another solution suggested for overcrowded homes was providing community centres so that older people can have space to enjoy activities that they cannot accommodate in their homes. One of the experts argued that design which considered privacy needs could be an important tool while designing affordable care homes, which usually have shared rooms occupied by two to three older people. 


\subsection{Emotional factors}

All the experts unanimously agreed that architectural design which supported older people's physical and psychological needs and enabled them to function independently on a daily basis would be considered as human-centric design.

One of the experts recommended that integration of user-friendly assistive technologies with architectural and interior design was an effective future strategy that should be explored by China. Additionally, the traditional courtyard housing model of China was considered a good example of human-centric design as it provides a balance of private-public space. Unfortunately, the experts noted that current mainstream housing in urban China is mainly mass housing which fails to satisfy the needs of older people. In such cases, some of the experts indicated that the onus of human-centred care would lie on better community design. Experts suggested displaying photos of children, memorabilia, having pets and having space to engage in social activities as simple methods to reduce loneliness. Some experts recommended that instead of focusing on design for older people, designers should concentrate on lifetime housing which could be adaptable as people aged.

Usually Chinese older people do not want to move to care homes as they do not feel attached to the new surroundings, hence it was deemed very important by all experts that care homes employ a sensitive design approach to make older people 'feel at home'. Additionally, most experts reported that maintaining older people's dignity and privacy in a care home was key to making them feel comfortable. Two of the experts noted that the current care homes in China either felt like a 'hospital' or a 'hotel'. In other words, some of the care homes were too institutional while others were luxuriously built to impress, but either ways they both lacked the personal homely feeling. Some of the care homes have tall, immaculately decorated entrance lobbies which lack the intimate and pleasant scale of a home. In some instances, the dining and social areas felt very institutional. The experts recommended that dining areas needed to be designed more casually with smaller dining tables, sofas and break out spaces, as they were a hub of social activity. Experts also suggested that older people in care homes should be allowed to bring their own furniture, memorabilia, reposition their décor and have freedom to personalise their space according to their needs and lifestyle. Also it was very important to provide private social spaces in care homes which could be used when family and friends visited.

\subsection{Community}

The experts concurred that designing a better community environment not only includes the physical aspects such as a barrier-free design, open spaces, walkways, public toilets and outdoor seating but also cultivating a sense of community. Most experts agreed that the design of community spaces should be conducive to older people's social life, encourage activities and multigenerational interaction. It was suggested that well-designed communities should provide services such as health care facilities (consultancy and emergency), convenience shops, fitness facilities, activity rooms, cafes, day care, night care, food delivery, etc. The consideration of safety and accessibility were important but it was equally important to ensure that the design did not feel 'like a hospital'. One of the experts suggested that traditional teahouses and cafes should be encouraged in the communities which could act as 'focal points' for older people to congregate and share experiences with younger generations. It had recently been observed that some of the current cafes and teahouses in urban China were a bit 'upscale and alien' for older people to use comfortably. The experts recommended the use of design to create memory triggers by incorporating sensory elements such as colours, sounds, landscape, etc.

The experts shared that some well-organised communities were providing services to older people such as checking up on them socially, providing free telecare bracelets and large button telephones to contact during an emergency, help buying groceries and medicines and providing gym equipment in public parks. Additionally, it was reported that small-scale community run care homes were gaining popularity as older people preferred to live within their familiar community, near their children and friends, while enjoying the option to have care and health services.

The barrier with regards to community design as noted by most experts was the lack of space, limited resources and funding. One of the experts narrated that many of the developers in charge of community centres had built them in underground spaces as these did not generate any profit. Such spaces were undesirable and largely unused by the community. It was felt that such situations could be remedied through government funding and strict policies and regulations.

\subsection{Technology}

The one-button emergency call system which contacts hospitals, family and neighbours in times of emergency was one of the most favoured assistive technology (AT) by most experts. This technology had quite a mixed response, as most experts noted that it granted older people with some level of safety and independence but reported that this technology was not yet properly supported by the Chinese care services. They believed that due to the current lack of services, infrastructure, legislation and regulations, there was a massive disconnect between technology and the Chinese care system. Medical and health related AT such as those used to monitor and report health statistics (blood pressure, glucose levels, etc.) were also considered important by the experts, followed by telecare pendants and bracelets. Additionally it was reported that smart home technologies that improved indoor environmental quality such as voice controlled and motion sensor activated lights, air purifiers, air conditioners and humidifiers were equally necessary. AT which would help combat loneliness and social isolation, such as video chatting, smartphones and those that assist with failing memory such as cooking hobs with automatic shut off, medicine reminders were also discussed positively.

A common theme that emerged through all the interviews was that AT was perceived to be expensive and its affordability would be a major issue hindering their uptake. One of the experts suggested that government funding and sharing of some AT by the community, could be economical solutions. Most experts observed that older people of the next generation would be more receptive to and make better use of technology, though there will still be new technologies which the next generation may never know how to use due to reduction in learning ability and other sensory difficulties faced by older people. Hence it was unanimously agreed that AT 
designed specifically for older people must be 'easy to use' and meet all their needs by not being too advanced and complicated to operate. Raising awareness to educate and encourage older people to use AT was also noted.

\subsection{Discussion}

The interview results concur that ageing-in-place can be a viable housing choice for people in China if not only the physical needs but the psychological needs of older people, such as companionship, family values, traditions, are satisfied. The experts had similar views on what guided Chinese older people's housing choice and the following reasons were highlighted for ageing-in-place:

1) To save money as good care homes were unaffordable

2) Tradition of familial care and support

3) To live with family

4) Help raise grandchildren

5) Continue to live within their familiar home and community

6) Sense of independence, freedom and belonging

7) Care homes in China are not up to the standard (staff is not well-trained, institutional environment)

8) Societal pressure and embarrassment associated with moving to a care home

9) Children find visiting care homes too inconvenient

Though ageing-in-place is considered the future of ageing in China there were concerns raised about the level of support available and the limitations due to age and health. It was argued that relatively healthy older people, probably in their 60 's and 70 's, were more likely to age-in-place. But as people grew older and were afflicted by health conditions that affected their mobility, cognition, etc., they were more likely to move to care homes or be moved by their children who worried about them. Most experts observed that China was currently at an early developmental stage with regards to the services and facilities that would enable older people to age independently in their own homes. This situation could be improved through better building design standards for older people, government support, infrastructure, legislation and regulations, coordination between technology and the Chinese care system. The interviews revealed current challenges which inhibited older people from ageing in their own homes and neighbourhoods, which included:

1) Crowded mass housing

2) External addition of lifts leads to blockage of views, excessive noise and reluctance among residents to share costs

3) Community design is hampered due to the lack of space, limited government funding and inadequate policies and regulations

4) Refurbishment of old residential buildings is difficult due to limited space, inadequate light and ventilation and structural inflexibility

5) Unwillingness of older people to engage in home refurbishment due to meagre pension and savings, conservative consumer attitude, lack of time and effort, saving money for their family and lack of awareness

6) AT is perceived to be expensive and its affordability is a huge hindrance to its uptake

In terms of financial barriers, it was speculated that the rapidly changing economic scenario and rise of consumerism in China would contribute to a new generation of older people who are willing to spend money on their future as opposed to the current older population which belonged to a past that fuelled their frugal lifestyle. The experts also observed that there was some existing potential which needed to be further explored so as to enable older people to age-in-place better. These positives included the traditional Chinese courtyard housing model, effective government policies, services provided by the community and community run care homes.

\subsection{Conclusion}

The interview findings have revealed the challenges, potentials and needs of older people in China as experienced by the experts through their research as well as designing projects for older people in China. The findings of this research will help fill the knowledge gap present in the current housing models in China so that they can be significantly age-friendly and establish innovative design solutions which take into account the cultural, social, economic and political contexts. This research could potentially benefit a range of stakeholders, i.e. decision makers and local governments; architects, interior designers, product designers; health and social care professionals; and professionals from the AT industry, to guide better design and to meet older people's needs in the future.

To conclude, this research proposes some recommendations, which include:

1) Human centric design that promotes health and safety and is supportive of physical and psychological needs of older people

2) Traditional Chinese courtyard housing design with incorporation of new environmentally-friendly technologies for better thermal comfort, lighting, acoustics, etc.

3) Detailed building design standards for older populations with focus on health and ergonomics; information on AT; design flexibility; sensitive to needs; and cater to the significant differences in the northern and southern parts of China

4) Encourage refurbishment of homes through government funding, subsidiaries and raising awareness of modern design and technologies

5) Improve crowded multigenerational homes through multifunctional furniture; multifunctional, co-working spaces; sensitive design for varied lifestyles and habits; better acoustics; features to improve natural light; well-designed storage; circulation spaces; and access to local community centres

6) Design to create memory triggers by incorporating sensory elements

7) Blend institutional aspects associated with age-friendly design with the rest of the décor 
8) Create a familiar homely environment in care homes through an intimate and pleasant scale; casual dining areas with sofas and break out spaces; scope to personalise space with their own furniture, memorabilia, photos; and having pets

9) Improved community design with scope for social activities, multigenerational interaction, professional care, health care facilities, fitness facilities, cafes and food delivery

10) Integrate user-friendly assistive technologies (AT) with architectural and interior design

11) AT designed specifically for older people that is 'easy to use', meets all their needs and is not complicated to operate

12) AT that, assists during emergencies; monitors and reports health conditions; maintains improved indoor environmental quality; helps combat loneliness and social isolation; and assists with failing memory

13) Government funding for AT and its sharing by the community

14) Raise awareness to educate and encourage older people to use AT

\section{Acknowledgements}

This research is co-funded by the Economic and Social Research Council (ESRC), UK; L'Agence Nationale de la Recherche (ANR), France; and National Science Foundation of China (NSFC), China. We would like to thank all the experts who took the time to contribute to this research with their valuable insight and knowledge.

\section{References}

Agile Ageing Alliance. (2017). Neighbourhoods of the Future: Better Homes for Older Adults - Improving Health, Care, Design and Technology. London: A Creative Skills for Life Production.

Best, R., \& Porteus, J. (2016). HAPPI 3 Housing our ageing population: Positive Ideas- Making Retirement Living A Positive Choice. London: All Party Parliamentry Group on Housing and Care for Older People.

Burmeister, O. K. (2010). Websites for seniors: cognitive accessibility. International Journal of Emerging Technologies and Society, 8(2), 99.

China Health and Retirement Longitudinal Study. (2013). Retrieved from China Health and Retirement Longitudinal Study (CHARLS): http://charls.pku.edu.cn/en

CIIC China. (2016). In China, the number of people who aged 60 and over is 222 million. Retrieved from China's ministry of civil affairs: http://news.china.com.cn/201607/12/content_38858935.htm

Dahlan, A., \& Sultanlbrahim, S. A. (2017). An Activity Program for Older People. Asian Journal of Quality of Life AjQoL, 2(6), 1-10.

Danziger, S., \& Chaudhury, H. (2009). Older adults' use of adaptable design features in housing units: An exploratory study. Journal of Housing for the Elderly, 23(3), 134-148.

Davey, J., de Joux, V., Nana, G., \& Arcus, M. (2004). Accommodation options for older people in Aotearoa/New Zealand. Christchurch: . Christchurch: Centre for Housing Research Aotearoa/New Zealand (CHRANZ).

Faith, V., Hadjri, K., Rooney, C., Craig, C., \& McAllister, K. (2015). Finding a way: long-term care homes to support dementia. Proceedings of the Institution of Civil Engineers: Urban Design and Planning, 168(DP4), 204-217.

Feng, W. (2014). The Silver and White Economy: The Chinese Demographic Challenge. In OECD, Fostering resilient economies: demographic transition in local labour markets. Secretary-General of the OECD. Retrieved from https://www.oecd.org/employment/leed/OECD-China-report-Final.pdf

Gao, X. (2013). Preference of the Urban Elderly for Caring Facilities: Variation across Different Communities. China Soft Science, 2013(1), 103-114.

Gibson, G., Dickinson, C., Brittain, K., \& Robinson, L. (2015). The everyday use of assistive technology by people with dementia and their family carers: a qualitative study. BMC GERIATRICS.

Gupta, R., Barnfield, L., \& Gregg, M. (2017). Overheating in care settings: magnitude, causes, preparedness and remedies. Building Research \& Information, 45(1-2), 83-101.

HACT. (2016). Is housing really ready to go digital? A manifesto for change. London: HACT.

Hadjri, K., Afacan, Y., \& Gadakari, T. (2016). Inclusive Design. In M. Noguchi, ZEMCH: Toward the Delivery of Zero Energy Mass Custom Homes (pp. 151-173). Switzerland: Springer.

Hussein, H., Abidin, N. N., \& Omar, Z. (2016). Sensory Gardens A multidisciplinary effort. Asian Journal of Behavioural Studies AjBeS, 1(1), 31-40.

Hussein, H., Omar, Z., \& Ishak, S. A. (2016). Sensory Garden for an Inclusive Society. Asian Journal of Behvioural Studies AjBeS, 1(4), $33-43$.

Iwarsson, S., \& A, S. (2003). Accessibility, usability and universal design--positioning and definition of concepts describing person-environment relationships. Disability and rehabilitation, 25(2), 57-66.

Iwarsson, S., \& Wilson, G. (2006). Environmental barriers, functional limitations, and housing satisfaction among older people in Sweden: A longitudinal perspective on housing accessibility. Technology and Disability, 18(2), 57-66. 
Jennings, L., Hadjii, K., \& Abdelmonem, G. (2012). ICT-uptake in older peoples' home environments. Gerontechnology, 11(2).

Kang, M., Lyon, M., \& Kramp, J. (2012). Older Adults' motivations and expectations toward senior cohousing in a rural community. Housing and Society, 39(2), 187202.

Labonnote, N., \& Høyland, K. (2015). Smart home technologies that support independent living: challenges and opportunities for the building industry - a systematic mapping study. Intelligent Buildings International, 9(1), 40-63.

Lawler, K. (2001). Aging in Place: Coordinating Housing and Health Care Provision for America's Growing Elderly Population. Washington: Joint Center for Housing Studies of Harvard University \& Neighbourhood Reinvestment Corporation.

Li, B. (2010). Polarisation and features: The living arrangement of Chinese older people. Chinese Journal of Population Science, 2010(2), 101-112.

Local Government Association; Institute of Public Care. (2016). Transforming social care through the use of information and technology. London: Local Government Association.

Ministry of Housing and Urban-Rural Development of People's Republic of China (MOHURD) \& General Administration of Quality Supervision, Inspection and Quarantine of the People's Republic of China (AQSIQ). (2017). Code for design of residential building for the aged. Beijing: China Architecture \& Building Press.

Muhammad, Z. (2016). Community- Based Projects in Nigeria. Asian Journal of Quality of Life AjQoL, 1(4), 11-21.

National Bureau of Statistics of the People's Republic of China. (2016). The public service needs research based on home-based care model. Retrieved from National Bureau of Statistics of the People's Republic of China, Zhejiang investigation team: http://www.zhejiang.gov.cn/art/2016/5/30/art_5499_2125063.html

OECD. (2014). Fostering Resilient Economies: Demographic Transition in Local Labour Markets. Secretary-General of the OECD.

Pannell, J., \& Blood, I. (2012). Supported Housing for Older People in the UK: An Evidence Review. London: Joseph Rowntree Foundation.

Renaut, S., Ogg, J., Petite, S., \& Chamahian, A. (2015). Home environments and adaptations in the context of ageing. Ageing and Society, 35(6), 1278-1303.

Roelofsen, P. (2014). Healthy ageing - Design criteria for the indoor environment for vital elderly. Intelligent Buildings International, 6(1), 11-25.

Shu, K. (2006). The Chinese urban housing ownership rate is on the top of the world, buying property to live is dangerous. China Economic Weekly, 2006(24).

Stones, D., \& Gullifer, J. (2016). 'At home it's just so much easier to be yourself: older adults' perceptions of ageing in place. Ageing and Society, 36(3), 449-481.

Tian, Q. (2010). Community care for the elderly: comparative study based on welfare pluralism (Doctoral dissertation). Shanghai: East China Normal University.

Torrington, J. (2014). Future of an ageing population: evidence review. London: Foresight, Government Office for Science.

Twyford, K. (2016). Individuals with dementia living in extra care housing: an initial exploration of the practicalities and possibilities. London: Housing Learning \& Information Network.

United Nations. (2013). World Population Prospects: The 2012 Revision Population Database. New York: United Nations.

Walker, M. (2017). Creating homes that people would like to live in rather than have to live in: Is there a role for occupational therapists in the design of housing? London: Housing Learning \& Improvement Network.

World Health Organisation. (2011). Global Health and Aging. National Institute on Aging, National Institutes of Health, World Health Organisation.

World Health Organization. (2007). Global Age-Friendly Cities Project: A Guide. Geneva: WHO Press.

Yousefi, Z., Hosseini, S.-B., Yazdanfar, S.-A., \& Norouzian-Maleki, S. (2017). Promoting the Residents' Sense of Belonging in Housing Design. Asian Journal of Behavioural Studies AjBeS, 2(5), 33-43.

Zakariya, K., Harun, N. Z., \& Mansor, M. (2016). Space and Sociability: Mapping Melbourne's City Square. Asian Journal of Quality of Life AjQoL, 1(2), 45-55.

Zhang, J., Liu, H., \& Qi, Y. (2015). Living environment and life satisfaction of aged population in Beijing Municipality. Progress In Geography, 34(12), $1628-1636$.

Zhang, Y., \& Goza, F. W. (2006). Who will care for the elderly in China?: A review of the problems caused by China's one-child policy and their potential solutions Journal of Aging Studies, 20(2), 151-164.

Zhou, J., \& Walker, A. (2016). The need for community care among older people in China. Ageing \& Society, 36(6), 1312-1332. 